Environment Conservation Journal 15(1 \& 2)109-116, 2014

ISSN 0972-3099 (Print) 2278-5124 (Online)

Abstracted and Indexed

\title{
Sediment texture and nutrients of Muttukadu, sand bar built backwaters, Tamilnadu, India
}

\author{
G. Kalpana ${ }^{1} \bowtie$ and Usha Natesan ${ }^{2}$
}

Received:13.09.2013

Revised:22.01.2014

Accepted:19.02.2014

\begin{abstract}
Muttukadu backwater form a complex system of shallow estuarine network spread over an area of $0.87 \mathrm{~km}^{2} \mathrm{meant}$ for fishing and boating activities. The study area is connected to the sea by a bar mouth, the width of which is variable from a few meters to $200 \mathrm{~m}$ in different months. Mouth closes due to sandbar formation from March to September. A combination of reduced river discharge, the build-up of an oceanic bar as a result of onshore sediment transport by longperiod swell wave action during summer, cause the formation of sand bar. Sediments are the major sink for chemical components of water bodies and sediment chemical analyses afford methods for measurements of the quality of overlying water and the levels of potential pollutants. Station $1(0.5 \mathrm{~km}$ away from the mouth) and 9 which is in the sea is always sand dominated as they are influenced by the nearshore dynamics. The saline sea water, which enters the estuary, resuspends the flocculated sediments at the mouth and transports the fine floccules to the water column during the open condition. $\mathrm{pH}(7.7)$ of the sediment is high during monsoon season. The total nitrogen $(4.7 \mu \mathrm{g} / \mathrm{L})$ of sediments is higher during summer season due to the oxidation of dead plant organic matter, which has settled on the top layer. Total Phosphate shows a positive correlation with silt. Phosphorus load is high in the stations 5, 6, 7 and 8 is 2.3, 2.1, 4 and 2.5 $(\mu \mathrm{g} / \mathrm{L})$ which is located in the upstream of the backwater and in Buckingham canal compared with the mouth region, indicating that the environment is substantially influenced by local sources of sewage, industrial effluent etc.
\end{abstract}

\section{Keywords: Buckingham canal, Cluster analysis, Muttukadu backwater, Nutrient, Sand bar, Sediment texture}

\section{Introduction}

Estuarine sediments and waters are characterized by specific and complex physical, chemical and microbiological properties. These properties depend and interact with each other and collectively constitute a unique environment to the organism. The study of sediments represents a useful tool for determining the actual state of environmental pollution of a water body. Textural characteristics of estuarine sediments are strongly influenced by several factors, including source area composition of adjacent lands, climate, length and energy of sediment transport, redox conditions in the depositional environments (Fralick and Kronberg, 1997). It is well recognized that the primary productivity in shallow marine environment depends on nutrients economy which is known to be governed by the sediment nutrient level. Knowledge on the role of sediments in this is useful in determining the sediment-water interactions eventually affect the productivity of the overlying

\section{Author's Address}

Centre for Water Resources,Anna University Chennai, Chennai Email: gkalpana1@gmail.com water body (Venkatasamy and Hariharan, 1986). According to Tennore, (1981) nitrogen is the major regulatory nutritional factor in most detrital based system. Sreenivasan (1976) reported that, the bottom sediment is the main source for different forms of nitrogen. The physicochemical character of sediments regulates the type of food, feeding and other life activities of benthic forms to a great extent (Ramachandra et al., 1984). The variability of freshwater discharge at the upstream boundary is a major control on sediment concentration and transport (Schubel and Prichard, 1986; Sharp et al., 1986; William, 1989; Rajasegar et al., 2002). Soil acts as a reservoir of nutrients and several biogeocycling, exchange of nutrients takes at bottom water interface. Nutrients are also derived from the drainage water and mineralization of organic matter. Many studies have been carried out so far on sediment nutrients from various estuaries of India (Remani et al., 1980; Murthy and Veerayya, 1981; Sivakumar et al., 1983; Sesamal et al., 1986; Nair et al., 1987; Satyanarayana et al., 1993; Seralathan et al., 1993; Rajasegar et al., 2002; 
Venkatraman et al 2010). The present study was carried out on the seasonal composition, texture and distribution of nitrogen and phosphorus of sediments in the Muttukadu Backwater. The present study will be useful tool for future ecological assessment and monitoring of this Backwater.

\section{Material and methods}

Muttukadu (Kovalam) Backwater (latitude $12^{\circ}$ $46^{\prime} \mathrm{N}$ and longitude $80^{\circ} 18^{\prime} \mathrm{E}$ ) is located at $36 \mathrm{~km}$ south of the Chennai, Southeast coast of India. The geology of the study area is represented by the basement Archean charnockite rocks which are overlain by a thick mantle of quaternary alluvium and these in turn overlain by the Holocene tidal flat deposit and coastal dunes (Achyuthan, 2006). The coastal beach area at Muttukadu is characterized by salt marsh and barrier dunes and forming paleoshorelines and a spit. The study area is connected to the sea by a bar mouth, the width of which is variable from a few meters to $200 \mathrm{~m}$ in different months. Backwater is normally cut off from the sea between March and September, when a sand bar is formed. During October-December due to inundation by the water from the upper reaches, sand bar gets eroded and the connection with the sea is restored. A spit of sand protects the low lying marshy land at Muttukadu (Achyuthan et al., 2009). The site selection was based on their proximity to sand bar and the level of anthropogenic pressure.

Monthly sediment samples were collected from nine stations (Fig. 1) in Muttukadu Backwater for a period of one year from January-December 2009.

- Station $1-0.5 \mathrm{~km}$ away from the mouth

- Station $2-1.5 \mathrm{~km}$ from the mouth near TTDC Boat house

- Station 3-2 km distance from the mouth

- Station 4-3 km from the mouth near crab culture

- Station 5-4 km from the mouth

- Station 6-6 km from the mouth near Industrial outlet

- Station 7 and $8-1.5 \mathrm{~km}$ and $2 \mathrm{~km}$ respectively from the mouth inside Buckingham Canal

- Station $9-0.5 \mathrm{~km}$ distance opposite to Muttukadu mouth in Bay of Bengal

Sediments were collected using Vanveen grab and were taken to the laboratory in clean polythene bags. The percentage composition of sand, silt and clay were determined by combined sieving and pipette method as described by Krumbein and Pettijohn (1938). Soil $\mathrm{pH}$ was recorded by $\mathrm{pH}$ meter. The sediment temperature was recorded by inserting the thermometer just below the surface of the sediment.

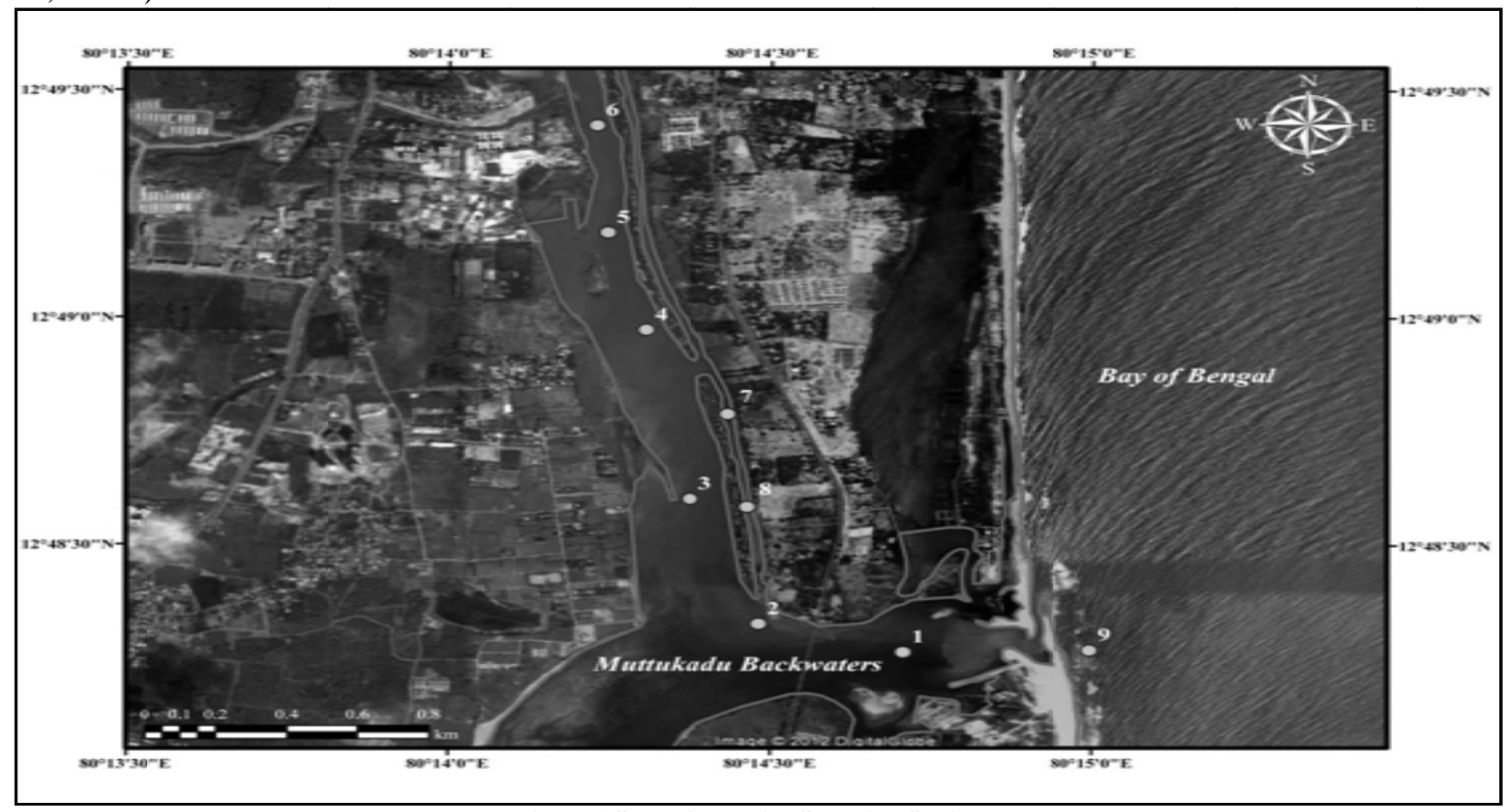

Figure 1 Study Area with Sampling Stations

110

Environment Conservation Journal 
Total nitrogen in the sediment was estimated by Kjeldahl method as out lined by Barnes (1959) and total phosphorus was determined by the method described by Rochford (1951). The north east monsoon in Chennai brings intense rainfall from October to December months. The pattern of rainfall facilitates various season of the year into post monsoon (January - March), summer (April June), Pre monsoon (July - September) and monsoon (October - December).

The seasonal variations of the environmental features in the estuarine system are chiefly controlled by the spectacular regime of the rainfall during monsoon. The data were subjected to statistical computations such as principal component analysis using statistica version 8 and microsoft excel stat and cluster analysis using PRIMER.Cluster analysis (CA) is to make objectives into groups based on the similarities inside of the group and dissimilarities of different groups.

The groups are divided by their unique characteristics, and often, it helps interpreting the data (Vega et al. 1998). Many studies have shown that CA reliably classifies surface water quality and can guide future sampling strategies (Wunderlin et al. 2001; Simeonov et al. 2003; Singh et al. 2004). In this study, hierarchical agglomerative CA wasperformed on the normalized data set by means of the wards method, using single Euclidean distances as a measure similarity (Simeonov et al. 2003; Shrestha and Kazama 2007).

Table 1. Descriptive statistics of the data along the study sites of Muttukadu Backwater from January to December 2009

\begin{tabular}{|l|r|r|r|r|r|r|r|r|r|}
\hline & \multicolumn{1}{|c|}{ Mean } & Median & \multicolumn{1}{c|}{ Min } & \multicolumn{1}{c|}{ Max } & Range & Std.Dev. & SD (+0.95) & SD (0.95) & Coef.Var. \\
\hline Sand & 90.22 & 91.00 & 59.90 & 99.70 & 39.80 & 9.56 & 7.92 & 12.08 & 10.60 \\
\hline Silt & 3.13 & 2.60 & 0.00 & 16.00 & 16.00 & 3.06 & 2.53 & 3.87 & 97.87 \\
\hline Clay & 7.40 & 3.40 & 0.00 & 39.10 & 39.10 & 9.32 & 7.72 & 11.78 & 125.93 \\
\hline pH & 7.08 & 7.00 & 6.50 & 7.50 & 1.00 & 0.20 & 0.17 & 0.25 & 2.83 \\
\hline Temp & 29.35 & 31.20 & 18.90 & 34.00 & 15.10 & 4.61 & 3.82 & 5.83 & 15.71 \\
\hline TN & 1.81 & 1.60 & 0.01 & 4.30 & 4.29 & 1.47 & 1.21 & 1.85 & 80.81 \\
\hline TP & 1.30 & 1.40 & 0.20 & 2.40 & 2.20 & 0.67 & 0.55 & 0.84 & 51.37 \\
\hline
\end{tabular}

Table 2. Correlation between different physico-chemical parameters of sediment along the study sites of Muttukadu Backwater from January to December 2009

\begin{tabular}{|l|l|l|l|l|l|l|l|}
\hline & Temp & pH & TN & TP & Sand & Silt & Clay \\
\hline Temp & 1.00 & & & & & & \\
\hline pH & -0.11 & 1.00 & & & & & \\
\hline TN & -0.38 & 0.01 & 1.00 & & & & \\
\hline TP & 0.08 & -0.18 & 0.54 & 1.00 & & & \\
\hline Sand & 0.15 & 0.10 & -0.57 & -0.43 & 1.00 & & \\
\hline Silt & 0.24 & -0.38 & 0.13 & 0.46 & -0.23 & 1.00 & \\
\hline Clay & -0.25 & 0.02 & 0.53 & 0.25 & -0.94 & -0.08 & 1.00 \\
\hline
\end{tabular}

Results and Discussion

The mean and standard deviation with standard depends on the source and texture of sediments error values of temperature, $\mathrm{pH}$, sediment supplied and topographic features of the area. In the composition, total nitrogen and total phosphorus are present study, the percentage composition of sand given in Table 1.

in sediment is higher during monsoon season or The sand, silt and clay contents of the study area when the mouth is open. This may be attributed to based on the opening and closing of sand bar are the winnowing activity of the monsoonal flood and presented in Figure 2. The sediment distribution in due to tidal activity. Higher clay content (24.6\%) estuaries and nearshore region to a large extent was observed during the post monsoon and summer 
while lower level (2.9\%) was found during monsoon. The higher value during summer may be attributed due to the fluctuations and settling of finer fractions and at high saline conditions, the clay and colloidal particles are neutralized and are drawn together into larger particles, which could settle faster than individual charged particle.The surface sediments in station 2 were found coarse in nature and the estimated sand content varies from 88 to $90 \%$. The transport of beach sand due to the tidal activity is the main reason for sand domination. When the mouth is fully open and closed, the clay is present in negligible amount but during the intermittently open condition, percentage of clay increases which may be due to riverine sediments or sludge from stations 7 and 8 . Sand dominance in stations 3 and 4 is due to tidal activity. Further during the open and closed conditions, an increase in silt content noticed due to flocculation of fine particles in the water column, sediment mixing and resuspension by organisms. Human activities i.e., boating also play a major role in concentrating the fine particles in the stations 3 and 4 of the Backwater.

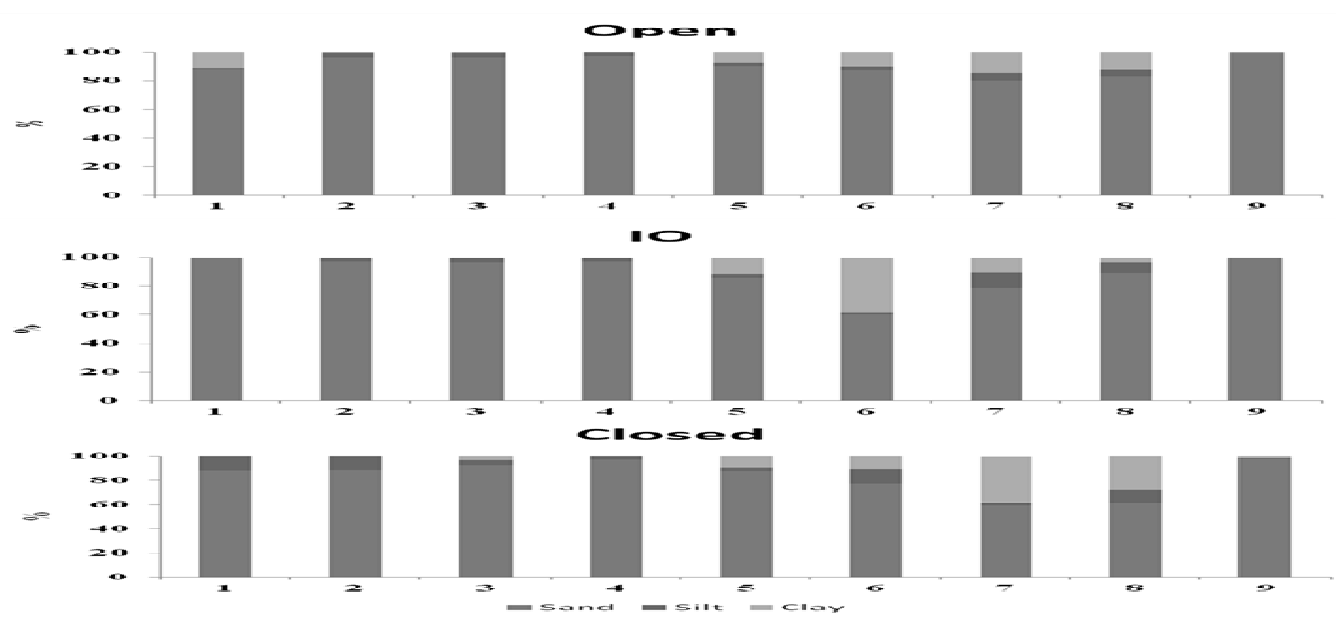

Figure 2 Sediment composition based on sand bar formation

Stations 5 and 6 in the upper reaches of the estuary is generally occupied by clayey silt. This confirms that the marine end is characterized by sand and the riverine end is characterized by silt and clay. Stations 7 and 8 in the Buckingham canal shows an increase in silt content due to large amounts of sludge deposition and microbial decomposition. Stations 1 and 9 was observed always sand dominated as they were influenced by the nearshore dynamics. The saline sea water, which enters the estuary, resuspends the flocculated sediments at the mouth and transports the fine floccules to the water column during the open condition. The tidal currents also plays a major role in removing the fine particles from the estuarine mouth and it can be seen clearly. $\mathrm{pH}$ of the sediment was high (7.5) during monsoon season. Low $\mathrm{pH}$ (6.5) was recorded during premonsoon. Higher value during summer could be due to a course of the redox changes in the sediment and water column apart from the influence of fresh water (Rajasegar et al., 2002). In the present study, sediment temperature was high $\left(33.9^{\circ} \mathrm{C}\right)$ during summer when the mouth is closed. Low temperature $\left(18^{\circ} \mathrm{C}\right)$ was recorded during monsoon season this could be due to fresh water inflow. High temperature during summer season is caused by ocean's large thermal inertia, which causes a lag between absorption and subsequent release of solar energy to the atmosphere. otal Nitrogen concentration varies from 0.01 to $4.7 \mu \mathrm{g} / \mathrm{g}$ (Figure 3).

The total nitrogen of sediments was higher (4.7 $\mu \mathrm{g} / \mathrm{g}$ ) during summer season due to the oxidation of dead plant organic matter, which has settled on the top layer. 

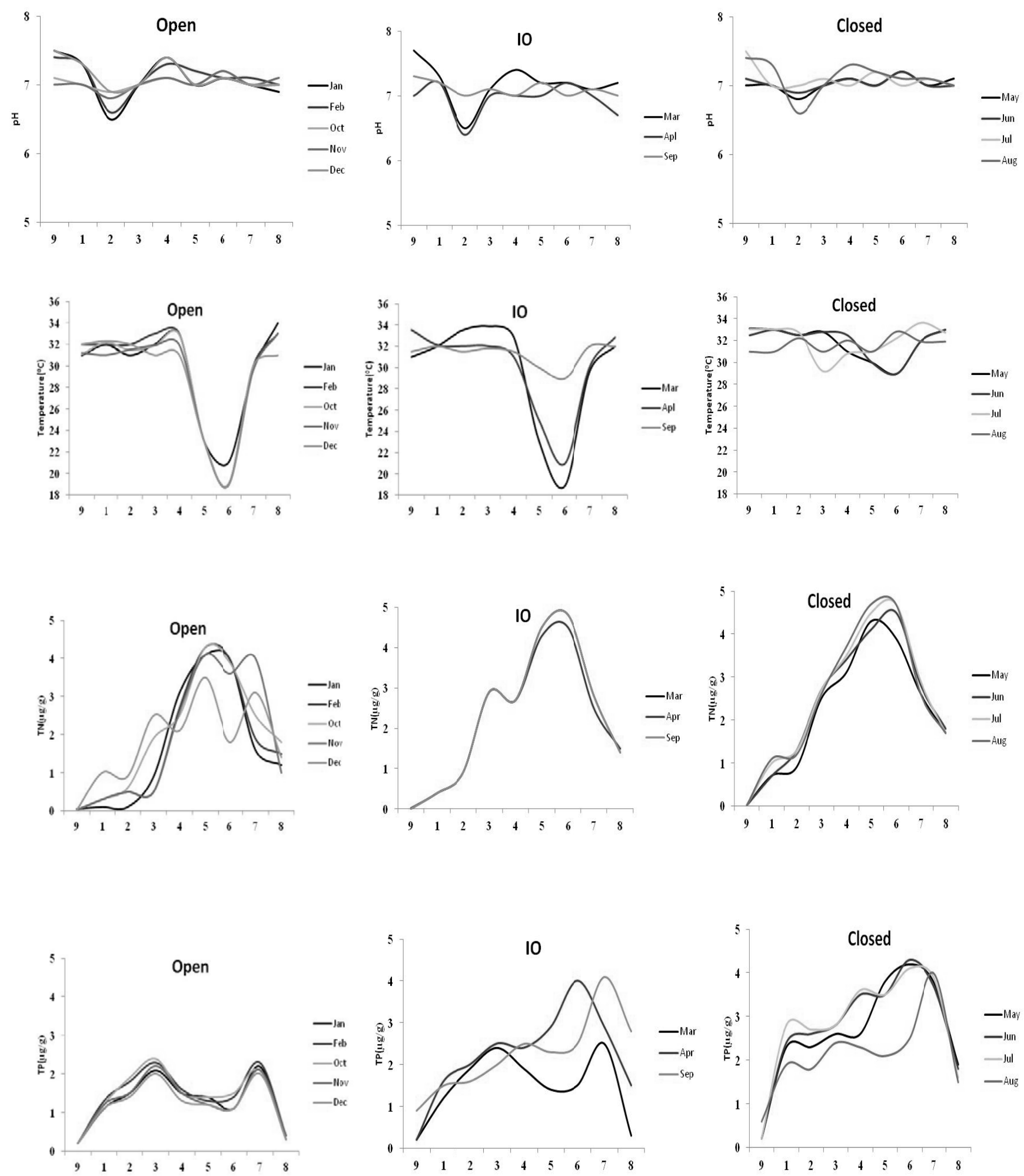

Figure 3 Variation in physico-chemical parameters based on sand bar formation 
The low values $(0.3 \mu \mathrm{g} / \mathrm{g})$ of total nitrogen observed during monsoon season may be ascribed to the low level of organic matter during monsoon season associated with higher sand. During pre and post monsoon periods, the fresh water flow is low but the nitrogenous effluents discharged from industries located in the upstream (Stations 5 and 6) would settle at the stations 3 and 4 . This might be the reason for the nitrogen increase in these regions. In the estuarine region (Stations 1, 2 and 3), total nitrogen shows a seasonal variation with the highest and lowest during post monsoon and monsoon respectively. The highest concentration of nitrogen during postmonsoon might be due to the contribution from organic detritus, the resulting from the planktonic bloom in these months and the decay of vegetation which reaches the bottom sediments by the relatively higher accumulation of organic materials in the sediments from overlying waters. Low TN during the monsoon observed in the stations 1 and 9 could be attributed coarse sandy texture. Clay and TN is positively correlated, from the main components of organic matter and are mostly associated with fine soil particles particularly clay (Table 2).Total Phosphate concentrations vary from 0.2 to $5 \mu \mathrm{g} / \mathrm{g}$ (Figure 3). The capacity of sediment to retain or release phosphorus is one of the important factors, which influence the concentration of inorganic/organic phosphorus in the overlying waters. Total phosphorus in the sediment was high and low (2.8 and $0.2 \mu \mathrm{g} / \mathrm{g}$ ) during summer and monsoon season Station 6 and 9 representing the upstream region and coastal water. The stations are clustered to different groups based on the distance from the mouth. Station 9 and 6 influence the transport of sediment. It is seen that clay from land discharge during the monsoon and sand from the sea forms a distinctive limiting factor in the distribution of nutrients when the mouth is open (Murthy and Veerayya 1981). The stations receiving maximum nutrient load due tourism and effluents from the industries group together. TN and TP form the first group when the mouth is closed. The stations which receive maximum urban sewage through Buckingham canal (e.g. 7 and 8) is grouped together in the CA analysis and they also form a part of a larger group. Biplot of sites identifies three clusters as i) mouth, ii) Buckingham canal stations respectively. The higher values are attributed to the dead organic matter settling from top and are related to the permeability of the sediments and the lower values may be due to the removal of top layer of sediments by heavy flood and deposition of sand. Stations 7 and 8 record the highest TP throughout the study period due to the accumulation of sludge from the domestic sewage during the summer season and also due to adsorptive tendency of phosphate is high with higher silt percentage. Further the transport of sludge by the movement of flow of water towards the mouth from station 8 could have also contributed to the adsorption of phosphorus compounds in the sediments of stations 1 and 2. The sandy texture of the sediment in stations 1 and 9 limits the seasonal variation of the sediment phosphate to considerably low levels compared to the upstream region of the backwater. Total Phosphate shows a positive correlation with silt (Table 2). Phosphorus load is high in the stations 5, 6, 7 and 8 compared with the mouth region, indicating that the environment is substantially influenced by local sources of sewage, industrial effluent etc.

\section{Cluster Analysis}

Dendrogram plot (fig4)based on the hydrographical condition provided a fairly convincing grouping of stations. Stations 1, 2, 3, 4 and 5 represent the conditions of estuarine mouth and the backwaters. Stations7 and 8 form another group, exhibiting the similarity of the Buckingham canal. 7 and 8 stations are highly influenced by anthropogenic activities as compared to other stations and iii) station 6 which form the dominant cluster indicating the influence of the upper reaches on backwaters.

\section{Conclusion}

From the present study it is concluded that the differences in nutrient concentrations and silt composition would have favoured the higher diversity and density of phytoplankton The sediment characteristics of Muttukadu are prone to changes which could arise from human activities such as domestic sewage, boating and industrial effluents. This call for management strategies geared towards the conservation and protection of environment. 


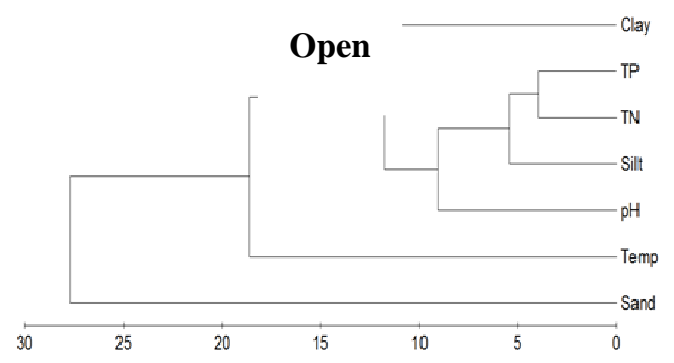

IO
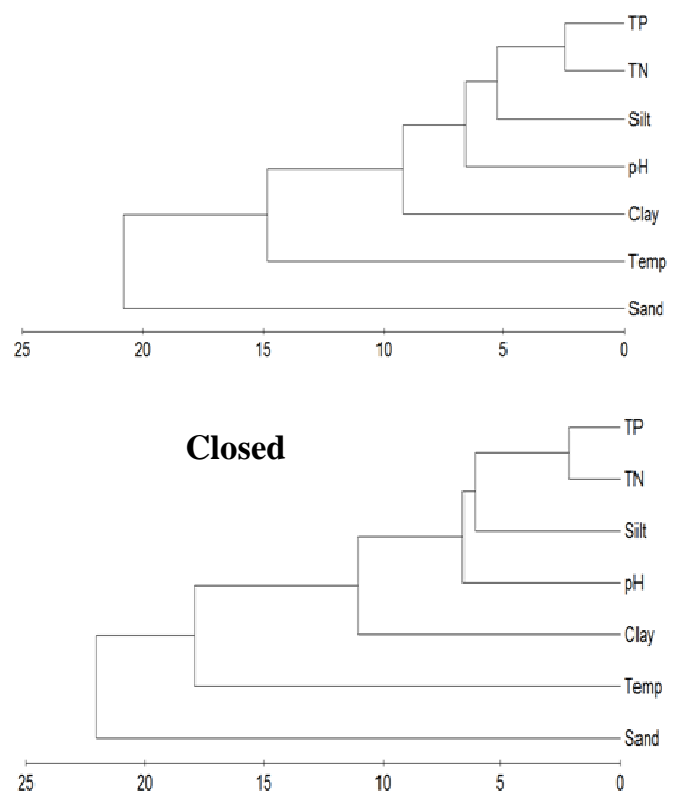

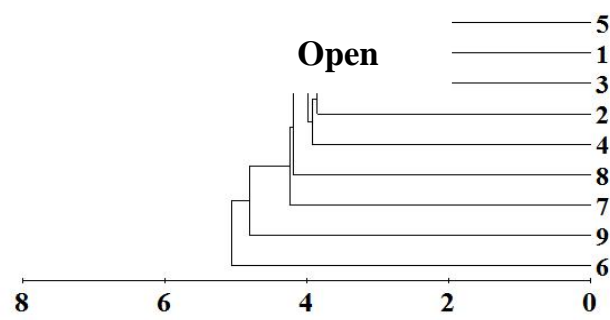

IO

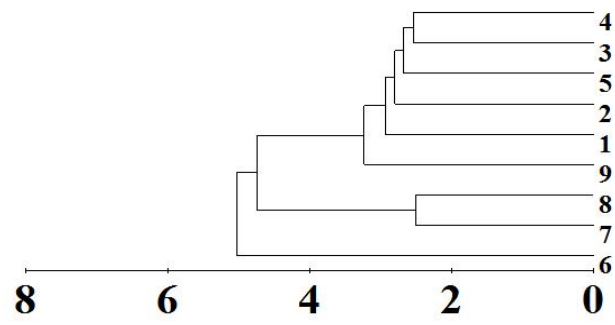

Closed

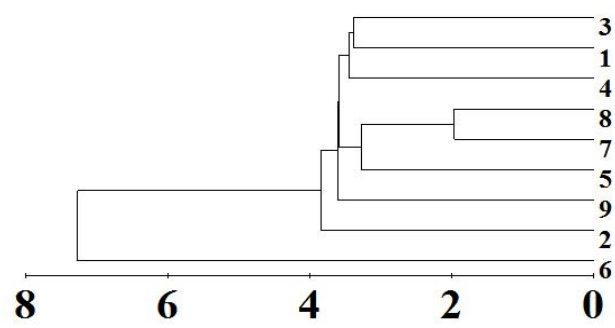

Figure 4 Station wise and parameter wise clusters based on sand bar formation for sediment

\section{Acknowledgment}

The authors are thankful to UGC for providing financial assistance to carry out this work under research by the "UGC- Meritorious Science Fellowship".

\section{References}

Achyuthan, H. 2006. Age and formation of Oyster beds of Muttukadu tidal flat zone, Tamilnadu. Current Science, 73 (50): $450-453$

Achyuthan, H., Uma, Maheshware, Gandhi, S., Mohammed, H. 2009. Foraminifera and Ostracods signatures for middle Holocene paleao-environmental change, Muttukadu, Chennai, India. Journal of the Palaeontological Society of India, Vol 54(1) 19-26.

Barnes, H. 1959 Apparatus and methods of oceanography. Part I. Chemical. G. Alen and Unwin Limited, London. p. 341.
Fralick, P.W., Kronberg 1997. B.I. Geochemical discrimination of clastic sedimentary rock sources. Sedimentary Geology, 113, pp 111-124.

Krumbein, W. C. and Pettijohn, F.J. 1938. Manual of sedimentary petrography. Appleton century crafts, New York. p. 549.

Murthy, P. S. N. and Veerayya, M. 1981. Studies on the sediments of Vembanad lake, Kerala state: part IV. Distribution of trace elements. Indian J. Marine Sci, 10, 165-172.

Nair, M. N. M., Harish, C. M. and Premchand, K. 1987. Vertical suspended sediment distribution. In: Beypore estuary. Proc. Natl. Sem. Estuarine. Management. Trivandrum. p. 38-43.

Rajasegar, M., Srinivasan, M. and Ajmal Khan, S. 2002 Distribution of sediment nutrients of Vellar estuary in 
relation to shrimp farming. Indian J. Marine Sci, 31:153156.

Ramachandra, U.T., Gupta, R. C. and Katti, R. J. 1984. Macrobenthos and sediment characteristics of Mulki estuary, west coast of India. Indian J. Marine Sci, 13: 109112.

Remani, K. N., Venugopal, P., Sarala Devi, K., Lalitha, S. and Unnithan, R. V. 1980. Sediment of Cochin backwater in relation to pollution. Indian J. Marine Sci, 9: 111-113.

Rochford, D. J. 1951 Studies on Australian estuarine hydrology. In: Introductory and comparative features. Aust. J. Marine Fresh Wat. Res, 2: 1-113.

Satyanarayana, D., Panigrahy, P.K. and Sahu, S. D. 1993. Texture, mineralogy, carbon nitrogen and phosphorus of Visakhapatnam shelf sediment, east coast of India. Indian J. Marine Sci, 22: 235-240.

Schubel, A. R. and Prichard, D. W. 1986. Response of upper Chespake bay to variations in discharge of the Susguehanna river. Estuaries, 9: 261-26.

Seralathan, P. N., Meenakshikutty, R. K., Ashrafe, V. and Padmalal, D. 1993. Sediment and organic carbon distribution in the Cochin harbour area. Indian J. Marine Sci., 22: 252-255.

Sesamal, S. K., Sahu, B. K. and Panigrahy, R. C. 1986. Texture and composition of sediments of Hooghly estuary and near shore environment. Indian J. Marine. Sci., 15: 201-202.

Sharp, J. H., Cifluentes, L. A., Cffin, R. B., Pennock, J. R., and Wong, K. C. 1986. The influence of river variability on the circulation, chemistry and microbiology of the Delare estuary. Estuaries, 9: 271-282.

Shrestha S., and Kazama F. 2007. Assessment of surface water quality using multivariate statistical techniques: a case study of the Fuji river basin, Japan. Environmental Modeling and Software., 22: 464-475.

Simeonov V., Stratis J. A., Samara C., Zachariadis G., Voutsa D., Anthemidis A. 2003. Assessment of the surface water quality in Northern Greece. Water Research. 37: 41194124.

Singh K. P., Malik, A., Mohan D., Sinha, S. 2004. Multivariate statistical techniques for the evaluation of spatial and temporal variations in water quality of Gomti River (India)—a case study. Water Research. 38: 3980-3992.

Sivakumar,V.,Thangaraj,G.S.,Chandran, R. and Ramamoorthi, K.1983.Seasonal variations in carbon, nitrogen and phosphorus in sediments of the Vellar estuary. Mahasagar Natl. Inst. Oceanogr. 16: 175-181.

Sreenivasan, A. 1976. Limnological studies and primary production in temple pond ecosystem. Hydrobiol. 48: 117123.

Tennore, K. R. 1981. Organic nitrogen and calorific content of detritus. I. Utilization by the deposit feeding polycheate, Copetella copetella. Estua. Coastshelf Sci., 12: 39-47.

Vega M., Pardo R., Barrato E., Deban, L. 1998. Assessment of seasonal and polluting effects on the quality of river water by exploratory data analysis. Water Research. 32: 3581-3592.

Venkatasamy, Reddy, H. R. and Hariharan, V. 1986. Distribution of nutrients in the sediments of the Netravathi Gurupur estuary, Mangalore. Indian J. Fish. 33: 123-126.

Venkatraman, S., Ramkumar, T and Anitha Mary. 2010. Textuaral Characteristic and Organic Matter Distribution pattern in Tirumalairajanar Estuary, Tamilnadu, EastCoast of India. Int.J.of Geomatic and Geoscience, Vol 1, No 3, 552-562.

William, G. P. 1989. Sediment concentration Vs water discharge during single hydrologic event in rivers. $\boldsymbol{J}$. Hydrology. 3: 89-106.

Wunderlin D. A., Diaz M. P., Ame M. V., Pesce S. F., Hued A. C., Bistoni M. A. 2001. Pattern recognition techniques for the evaluation of spatial and temporal variations in water quality. A case study: Suquira river basin (Cordoba- Argentina). Water Research. 35: 1894- 2881. 